\title{
Review Article \\ Potential of Biological Agents in Decontamination of Agricultural Soil
}

\author{
Muhammad Kashif Javaid, Mehrban Ashiq, and Muhammad Tahir \\ Department of Chemistry, University of Gujrat, Gujrat 50700, Pakistan \\ Correspondence should be addressed to Mehrban Ashiq; mehrban86@gmail.com
}

Received 5 December 2015; Accepted 8 March 2016

Academic Editor: Daniel Jun

Copyright ( 2016 Muhammad Kashif Javaid et al. This is an open access article distributed under the Creative Commons Attribution License, which permits unrestricted use, distribution, and reproduction in any medium, provided the original work is properly cited.

\begin{abstract}
Pesticides are widely used for the control of weeds, diseases, and pests of cultivated plants all over the world, mainly since the period after the Second World War. The use of pesticides is very extensive to control harm of pests all over the globe. Persistent nature of most of the synthetic pesticides causes serious environmental concerns. Decontamination of these hazardous chemicals is very essential. This review paper elaborates the potential of various biological agents in decontamination of agricultural soils. The agricultural crop fields are contaminated by the periodic applications of pesticides. Biodegradation is an ecofriendly, cost-effective, highly efficient approach compared to the physical and chemical methods which are expensive as well as unfriendly towards environment. Biodegradation is sensitive to the concentration levels of hydrogen peroxide and nitrogen along with microbial community, temperature, and $\mathrm{pH}$ changes. Experimental work for optimum conditions at lab scale can provide very fruitful results about specific bacterial, fungal strains. This study revealed an upper hand of bioremediation over physicochemical approaches. Further studies should be carried out to understand mechanisms of biotransformation.
\end{abstract}

\section{Introduction}

A pesticide can be defined as any substance or mixture of substances intended for preventing, destroying, repelling, or mitigating any pest (insects, mites, nematodes, weeds, rats, etc.). Pesticides like insecticides, herbicides, fungicides, and various other substances are used to control pests [1]. In modern agriculture practices, the extensive use of pesticides is very frequent to fulfill higher yield requirements. Millions of tons of pesticides are applied annually all over the globe, which covers the billions of dollars' market. The expenditures on pesticides were 35.8 billion in 2006 which rose up to 39.4 billion US dollars in 2007. Herbicides are most widely used in controlling of pests [2]. One of the primary concerns is to minimize harmful effects caused by the target organisms including viruses, bacteria, fungi, and insects [3]. The extensive use of pesticides causes serious environmental concerns, as only $5 \%$ or less from the applied pesticides reach the target organisms which resulted in contamination of soil and water bodies (major environmental problem of current age). The periodic use of pesticides makes the situation particularly perturbing. This repetition in the long term necessarily leads to an accumulation of pesticides and their residues in environment, endangering the entire population by their multifaceted toxicity [4]. There is a direct relationship between the contamination of pesticides and their residual detection [5]. In addition to causing toxic effects to humans, there is a high risk of contamination in ecosystem [6]. An enduring threat of volatilization of sprayed pesticides is present that usually hit (directly) nontarget vegetation. This leads towards contamination of air, soil, and nontarget plants [7]. There are chronic threats to human life, caused by long term, low dose exposure to pesticides. It can cause hormonal disruption, diminished intelligence, and reproductive abnormalities [8]. The constant mobility of applied pesticides through leaching, sorption, and volatilization results in contamination of different levels in the environment (Figure 1) $[9,10]$.

More than one kind of pesticide is applied for the control of different types of pests, as the classification of these substances can be accomplished on the basis of their use, mode of action, and chemical function. These include 


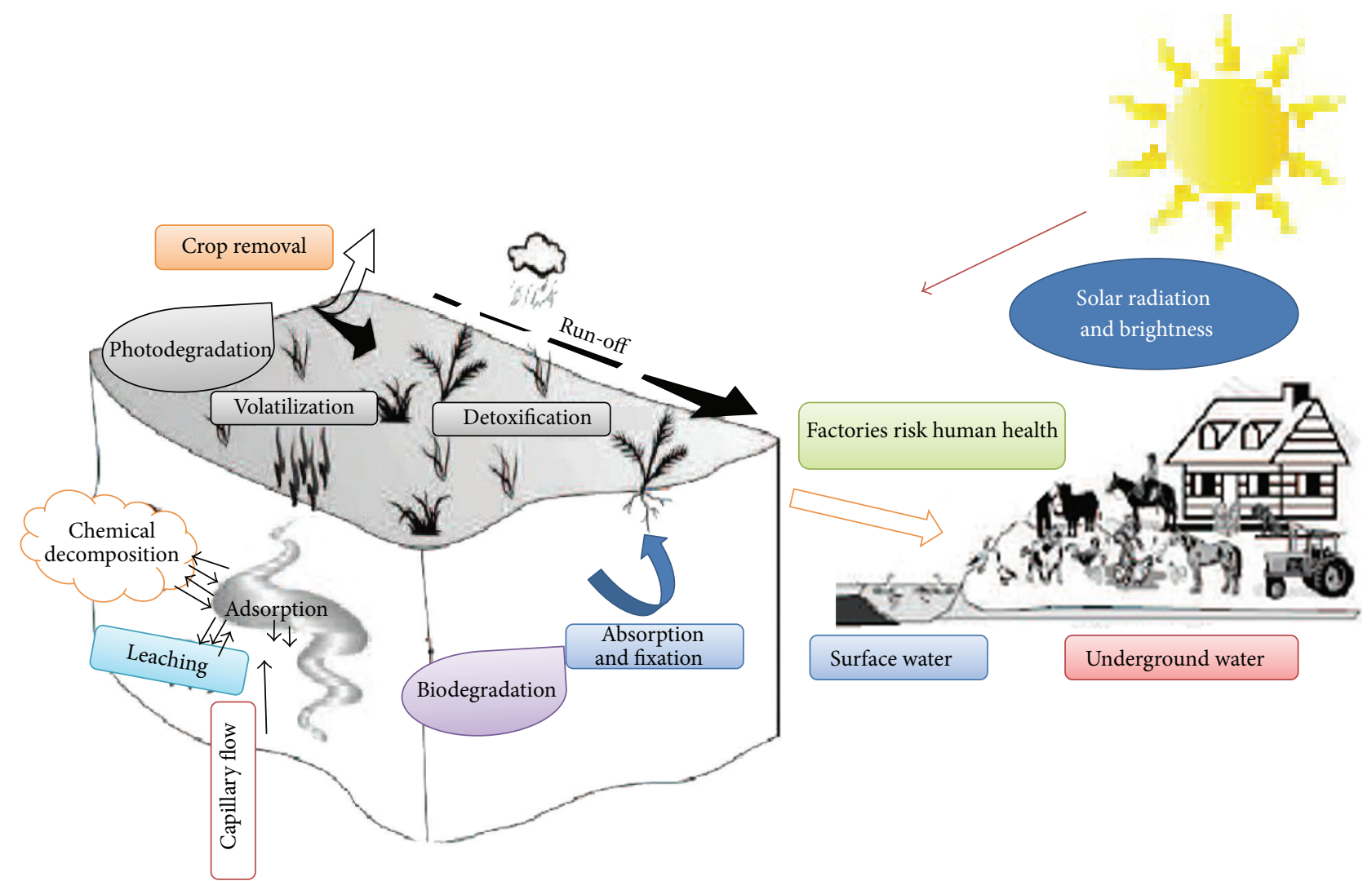

FIgURE 1: Pesticides contaminant and biodegradation in environment [11, 12].

insecticides for insects control, fungicides against fungi, rodenticide for rodents, and defoliant for leaf harvesting. There are some classes to which pesticides are classified on the basis of their chemical nature, that is, organochlorides, organophosphates, pyrethroids, and so forth. In present age, more than 500 different formulations of pesticides are used mainly in agricultural tricks. These formulations are in general artificially synthesized substances which are nonbiodegradable and enhance environmental toxicity. These nonbiodegradable compounds persist in agricultural fields after application. About three million people are intoxicated per annum as a result of pesticides usage, reported by the World Health Organization (WHO) [6]. The degradation of persistent pesticides is very essential for decontaminating soil and water bodies [13].

The pesticides degradation processes are of different modes, involved in decontamination of various systems in variable efficiency. The rate of degradation of pesticides is influenced by several factors which include chemical structure of pollutants, $\mathrm{pH}$ of soil, concentration of hydrogen peroxide, and concentration of iron. The rate of degradation differs as the pathway of this process changes. Acceleration of degradation processes results in decontamination in short span of time. Thus, photocatalytic degradation, biodegradation, ozonation, and photo-Fenton reactions are commonly evaluated for pesticides removal studies [14]. Microorganisms are present on earth as an uncountable number of species. These microbes are very vital for the bioremediation of pesticides. Endosulfan (pesticide) can be removed from environment by applying strains of microbes (Aspergillus) [15]. The phenomenon of biotransformations is very common and sometimes very essential for the survival of microorganisms, responsible for biodegradation of applied pesticides. There is a natural balance in between microbial evolution and bioremediation [16]. Biodegradation can be approached via microbes and also augmenting this process by artificial means. This approach to environmental decontamination possesses a number of benefits; for example, there is minimum chance of environmental disruption, economical, and fewer chances of secondary exposure alongside not causing damage to ecosystem [17, 18]. The isolation and characterization of microbial strains capable of degrading pesticides and their residues are of interest for the last two decades. In these microbes bacteria and fungi are the major degraders. Molecular probes can be used for the isolation and identification of degrading potential of microbial strains [18]. Ultimately organic matter decomposes as a result of microbial action. There is mismatch in synthetic and natural occurring pesticides so degradation rate differs in both cases, which is slow in case of synthetic pesticides (due to structural variations and less compatibility with metabolic pathways of applied microbes) [19].

Biodegradation methodology is widely used for the treatment of xenobiotics such as pesticides in soil. It is employed in many countries due to its low cost and being ecofriendly [20, 21]. Conventional approaches like land filling, recycling, and incineration are not very efficient and cost-effective. Different types of toxic intermediates are also formed during these 
processes [22]. In the present review, different approaches for biological degradation of pesticides have been discussed, in addition to analyzing (on the basis of reported literature) various factors affecting these modes of bioremediation.

\section{Different Approaches for Biodegradation}

Although a number of techniques are available for biodegradation, the ones of utmost importance are discussed here:

(i) Bacterial degradation.

(ii) Fungal degradation.

(iii) Enzymatic degradation.

2.1. Bacterial Degradation. The degradation of pesticides results in the production of carbon dioxide $\left(\mathrm{CO}_{2}\right)$ and water $\left(\mathrm{H}_{2} \mathrm{O}\right)$ by the oxidation of parent compounds. The bacterium involves in the degradation process energy intake from these degradation products. The efficiency of degradation process depends upon optimum atmospheric conditions, that is, temperature, $\mathrm{pH}$ of soil, moisture contents, and so forth. The modifications of different bacterial specimens via genetic mutations also enhance effectiveness of applied microbes. The biodegradable removal of pesticides has positive effects on the fertility of agricultural soil. Chlorpyrifos has a massive effect on contaminating soil and water bodies. Microbial degradation is very useful for the detoxification of such (chloroorganic) pesticides. The specific genes and enzymes are very critical for the cleavage of specific functional groups of the pesticide. The optimization of environmental conditions and an effective microbial community in the contaminated site is very essential for the degradation of pesticides [23].

There is a vital advantage of microorganism usage for degradation of pesticides. This is due to the diversity, wide distribution, and adaptation of variable metabolic pathways. The gene clusters are involved in microbial degradation. The genetic manipulation and construction of gene engineering bacteria are also used for degradation of pesticides [24]. Microbial strain screening and isolation are very effective for degradation of carbendazim in mineral culture medium. Carbendazim is carbon source for the growth of this strain. The $\mathrm{pH}$ range, 5.1-8.1, and temperature range, $25-40^{\circ} \mathrm{C}$, are optimum for maximum degradation efficiency, that is, up to $90 \%$ in nitrogen atmosphere [25]. Pesticide-degrading bacteria and Rhizobium meliloti coating on Medicago sativa seeds are effective for repairing soil, polluted by organic phosphorus pesticide. This approach is very efficient, possessing several advantages, that is, rapid soil repairing rate, simple operation, and high treating capability for removal of organic phosphorus pesticide [26, 27]. Sphingobium japonicum is a strain for degradation of chlorinated pesticides, that is, hexachlorocyclohexane. This strain (Sphingobium japonicum LZ-2) can completely decompose lindane $20 \mathrm{mg} / \mathrm{L}$ in 10 hours [28]. An aerobic bacterium (Burkholderia cepacia strain $\mathrm{CH}-9$ ) can be used for degradation of imidacloprid and metribuzin. $69 \%$ degradation of imidacloprid and $86 \%$ degradation of metribuzin can be obtained in 20 days with initial dose of $50 \mathrm{mg} / \mathrm{L}$ in mineral salt medium [29]. Bifenthrin (BF) is a synthetic pesticide. It is degraded by pyrethroid bacteria (Acinetobacter calcoaceticus). The degradation rate could be achieved up to $56.4 \%$ with initial concentration of $100 \mathrm{mg} / \mathrm{L}$ with $\mathrm{pH}$ range of 6.0-8.0 and 5\% inoculation [30].

Streptomycetes strains have enormous applications for degradation of chlorpyrifos (CP) pesticide. The degradation potential of these strains can be evaluated by performing study in agar medium. The $\mathrm{pH}$ alterations can affect the efficiency of degradation process [31]. Tert-Bu mercaptan (TMB) undergoes biodegradation in water under aerobic conditions. First-order kinetics are involved in biodegradation process. There is slight increase in rate of reaction by addition of TMB and slight decrease with addition of phenol [32]. Bacterial strains which are capable of degrading methomyl and carbofuran can be studied by high pressure liquid chromatography (HPLC) in biodegradation analysis. Acetonitrile and water were used as mobile phases. The closeness of carbofurandegrading strains to the genera Flavobacterium and Alcaligenes and that of methomyl degrading strains to genera Pseudomonas and Alcaligenes were observable by using $16 \mathrm{~S}$ rDNA sequence analysis [33, 34]. Photosynthetic bacterium (GJ-22) is capable of degrading cypermethrin (CMP). That CMP degradation by GJ-22 is very productive at $25-35^{\circ} \mathrm{C}$ and at $\mathrm{pH}$ of 7.0. By performing gas chromatography/mass spectrometry (GC-MS), metabolic products are detected. The degradation of CMP proceeds through oxidative or/and through hydrolytic pathways by GJ-22 yielding 5 metabolites [35]. The removal of organochlorine pesticides from soil is performed by microbial applications under optimum environmental conditions. Better results are obtained by addition of potassium humate for increasing concentration of microorganisms [36]. The strain of Pseudomonas putida and Pseudomonas mendocina has a great capacity of biodegrading permethrin and cypermethrin pesticides. Bioremediation up to $90 \%$ can be achieved with the help of these bacterial strains within the period of 15 days [37].

Acinetobacter sp. TW and Sphingomonas sp. TY strains are novel and very useful for the disposal of tobacco waste in the temperature range of $25-37^{\circ} \mathrm{C}$ and $\mathrm{pH}$ range of $7.0-$ 8.0 [38]. The actinomycete strain HP-S- 01 is isolated from activated sludge for its application to degrade deltamethrin. The degradation results in 3-phenoxybenzaldehyde as major hydrolysis product. This strain is highly efficient in degrading bifenthrin, fenvalerate, and fenpropathrin. This process undergoes first-order kinetics and provides an effective tool for bioremediation of environmental contamination from pesticides [39]. Diazinon degrading bacteria utilize it as a source of carbon and phosphorus under different culture conditions. The addition of carbon sources, as glucose or succinate, causes decrease in degradation rate [40]. Biodegradation of profenofos is conducted by bacterial strains isolated by enrichment technique. About $90 \%$ concentration of profenofos can be degraded in 90 hours [41]. Paracoccus sp. strain is applied for the biodegradation studies of pyridine. It was observed that, at the concentration of pyridine $<0.9 \mathrm{mg} / \mathrm{L}$, the rate of degradation is higher while at the concentration $>0.9 \mathrm{mg} / \mathrm{L}$ the rate is lower [42]. A bacterial 
consortium which degrades tetrachlorvinphos is isolated from agricultural soil. It is composed of six pure strains. The study reveals that these strains have a potential to degrade organophosphate pesticides [43].

Lactic acid bacteria can degrade organophosphorous insecticides by fermentation. Lactic acid bacteria use organophosphate as a source of carbon and phosphorus [44]. An effective and specific method is bacterial degradation of pyrethroid (a pesticide). Highly efficient bacterial strain of Enterobacter aerogenes can degrade many other pesticides, that is, bifenthrin, cypermethrin, and so forth [45]. Acinetobacter johnsonii (MA-19) strain was used for degradation study of organophosphate pesticides, by enrichment culture method. Four additional compounds were added to enhance efficiency, out of which $\mathrm{Na}$ succinate was very effective; by increasing its concentration the rate of degradation of malathion increased [46]. The same methodology was applied to degrade para-nitrophenol by Rhodococcus bacteria. It is an efficient bacterial decomposition method for para-nitrophenol [47]. Similarly, organophosphate pesticides degradation is carried out by using strains Bacillus, Actinobacteria, and L-proteobacteria [48]. Bacterium Bacillus thuringiensis is effective in degrading malathion in minimum salt media. With the addition of glucose and yeast, the growth of bacteria increases up to $10^{5}$-fold which degrades more than $99 \%$ malathion within 30 days. Residues were studied by HPLC and GC-MS [49]. Esbiothrin was degraded with much efficiency by immobilized Acinetobacter on magnetic polyurethane [50]. By using immobilized bacteria on Ca-alginate gel beads, organophosphate insecticide degradation was studied, along with hydrolyzed products [49].

Cyanobacteria and blue green algae convert fenamiphos into number of its stable, nontoxic components by using cultured technique [51]. Indigenous bacteria degrade sumithion OPs through anaerobic decomposition. They decompose them into $\mathrm{CH}_{4}, \mathrm{~N}_{2}, \mathrm{CO}_{2}, \mathrm{H}_{2} \mathrm{~S}$, and so forth [52]. Beans of green coffee can be used for the support and growth of bacteria (Stenotrophomonas maltophilia) which degrade DDT and endosulfan. A medium amended with glucose is used as a supplement [53]. Pseudomonas bacterium can degrade endosulfan. Whenever it bioaccumulates in fishes (Cyprinus carpio), it uses endosulfan as a carbon source $[54,55]$. Atrazine is degraded by Pseudomonas bacteria by two-phase biodegradation (unstable degradation products from first step further degrade to secondary components) [14]. Endosulfan is metabolized into endosulfan sulfate, which is the only product of endosulfan metabolism, by bacterial action. It resulted in 50\% degradation of endosulfan within three days [56]. A Gram negative bacterial strain (Sphingomonas) possesses high potential for degrading DDT [57]. Microscopic organisms (3 bacterial strains) potentially degrade mefenacet and many other amide pesticides such as propanil and metolachlor by hydrolysis [58].

Different types of pesticides (OPs, chlorinated pesticides, herbicides, and fungicides) are effectively degraded by the fermentation process carried out by Rhodobacter sphaeroides [58]. Screened bacteria are highly selective for the degradation of S-enantiomer of methylaxyl compared to its R-enantiomers at comparatively fast rate [59]. Vibrio and Shewanella bacteria can effectively degrade methyl parathion. Its biodegradation mechanism is entirely different from photocatalytic process [60]. Photosynthetic bacteria have capacity to degrade multiple types of pesticides (chlorpyrifos, phoxim, and triazophos) [61]. Ochrobactrum easily oxidize triazophos into its acidic form. It has the ability to degrade this pesticide up to $95 \%$ in crops [62]. Chlorinated pesticides can be degraded by using combination of aerobic-anaerobic decomposition with application of sugar solution. This is one of the very efficient methods for biodegradation of chlorinated pesticides [63]. Allethrin is a pyrethroid insecticide and its degradation is achieved by Acidomonas sp. [64]. Eight bacterial strains potentially degrade PCNP pesticide. Better results were obtained when all these strains were collectively used [65]. Two bacteria cad1 and cad2 degrade cadusafos in mineral salt medium with nitrogen (MSMN). They are also able to degrade ethoprophos nematicide completely [66].

Immobilized bacteria have capacity to degrade multiple pesticides (herbicides, fungicides, and carbamates) under different environmental conditions with different flow rates [67]. S-25 strain caused degradation (almost 100\%) of 2,4$\mathrm{D}$ organochlorine pesticide at optimum conditions, that is, temperature of $30^{\circ} \mathrm{C}$ and $\mathrm{pH}$ of 7.0 [68]. Aldrin (an organochlorine insecticide) is anaerobically degraded by microorganisms. These microorganisms used extracted yeast as carbon source [69]. Ethion (OPs) is anaerobically degraded by mesophilic bacteria. Other species are also capable of its degradation like Azospirillum and Pseudomonas [70]. Bacterial consortium, like Bacillus sp. and Chryseobacterium joostei, was used to compare biodegradation of lindane, methyl parathion, and carbofuran in individual and mixed pesticide enriched cultures by using biokinetic parameters. These bacteria use pesticide in their cometabolic pathways [71]. Psychrotrophic bacterium can degrade Me-parathion. This biodegradation is sensitive to $\mathrm{pH}$ and temperature variations [72]. Six genera are able to degrade organochloride pesticides, that is, endosulfan. Different genera have different potential to degrade them, from which Micrococcus and Pseudomonas were highly active compared to others [73]. Immobilized Escherichia coli (a well-known bacterium) could degrade organochlorine insecticide that contains ester bond [74].

The same bacterium is highly efficient in degrading a number of pesticides including BHC, DDT, endosulfan, $\mathrm{HCH}$ isomers, and 2,4-D [75-80]. DLL-1 bacterial strain biologically degrades pesticide that is present in soil and plant system [81]. Growth promoting rhizobacteria (GPRB) strains are effective in degrading fungicide and herbicide compared to Azotobacter and bacilli. The purpose was to determine the capacity of different bacteria to effectively degrade fungicides and herbicides [82].

2.2. Fungal Degradation. Fungi, from natural sources, can be screened out as an effective tool for biodegradation of toxic organic chemicals. A fungal strain Fusarium verticillioides is able to use lindane as a carbon and energy source under aerobic conditions. This strain can be isolated from Agave tequilana leaves by enrichment techniques. In the 
presence of limited nitrogen and phosphorus atmosphere, the efficiency in terms of higher degradation is achieved. The environmental factors and concentration of lindane and yeast extract improved the efficiency of the biodegradation process $[83,84]$. There is a great potential of fungal strains, that is, Fusarium oxysporum, Lentinula edodes, Penicillium brevicompactum, and Lecanicillium saksenae, for the biodegradation of the pesticides like terbuthylazine, difenoconazole, and pendimethalin in batch liquid cultures. These fungal strains are investigated to be valuable as active microorganisms for pesticides degradation [85]. Nonacclimated mixed culture of bacteria and white-rot fungus has applications for biodegradation of aldicarb, atrazine, and alachlor from the liquid phase, respectively. With incubation period of 14 days, mixed culture achieved 47,98 , and $62 \%$ removal, respectively. The removal of these pesticides is accompanied by phenomena of biosorption and biodegradation [86].

Methomyl and diazinon (pesticides) are biodegradable with the help of rot fungi isolates from contaminated soil. The optimum temperature for maximum efficiency is $28^{\circ} \mathrm{C}$. The rate of degradation is higher by using mixture of fungal strains [87]. Different fungal strains are observed for their degradation ability of DDD pesticide. The accumulation of these strains shows characteristic pattern for degrading process [88]. Endosulfan-degrading, aerobic fungal strains are effective for soil contaminated with organochlorine pesticides. These strains (Mortierella sp. strains W8 and Cm145) resulted in $50-70 \%$ degradation in 28 days at $25^{\circ} \mathrm{C}$. The diol formation of endosulfan firstly and then endosulfan lactone conversion take place during degradation. This enhances fertility of agriculture land [89]. On similar basis, there is possibility of degrading mixed insecticides (DDT and chlorpyrifos) by using mixed fungal strains. When low concentration of mixed insecticides was used, the efficiency of degradation is observed to be high. The efficiency is observed in $26.94 \%$ and $24.94 \%$ degradation of DDT and chlorpyrifos, respectively [90]. Under harsh conditions, Sphingomonas yanoikuyae strain can degrade carbamate and pyrethrin (OPs) with high efficiency in enrichment culture method, analyzed by gas chromatography [91]. Salt resistant actinomycete is capable of degrading carbofuran. One of seven actinomycetes, S. alanosinicus, is most effective and gives up to $95 \%$ degradation. It uses carbofuran as a carbon source and is applicable to saline soils for its efficiency [92].

Water body and soil that are affected by endosulfan can easily be bioremediated by fungal strain (Aspergillus niger). The chlorinated pesticide endosulfan is metabolized through various intermediates by this fungus [15]. More than 30 microorganisms are capable of degrading the pesticides, out of which Gliocladium genus has maximum activity for selectively degrading carbofuran [93]. Fungus uses chlorpyrifos as a carbon and energy source and causes its rapid degradation. Another fungus, basidiomycetes, degrades chlorpyrifos very effectively [94]. A fungus, C. elegans, degrades DEET, an insecticide, into different less toxic metabolites analyzed by HPLC-MS [95]. Phytopathogenic fungi easily degrade herbicides. This fungus easily grows up on organophosphonate herbicides and degrades them [96]. Trichoderma viride and T. harzianum have high potential to degrade pirimicarb.
Degradation capacity increases when activated charcoal is added [97].

2.3. Enzymatic Degradation. Enzymes produced during different metabolic pathways in plants as well as in microbes present in soil are the key for bioremediation of pesticides. Optimum environmental conditions support fast rate of removal of toxic intermediates. The engineered bacteria were used to produce esterase gene which specifically act on substrate and degrade more than 65\% methyl parathion within 3 hours [98]. Carbofuran, an insecticide present in contaminated soil, can be treated with Paracoccus sp. YM3, by MSM method, which enzymatically degrades carbofuran into its metabolites which were analyzed by HPLC. This bacterium uses carbofuran as sole source of carbon [99]. Genetically modified Escherichia coli enzymatically degrade methyl parathion and many other OPs, that is, PNP, which is detected by HPLC [100]. Micrococcus sp. has been found to have versatile ability to degrade OPs pesticide like cypermethrin by enzymatic action [101]. Lindane is degraded by fungus Conidiobolus through enzyme action. GC-ECD and GC/MS confirm that there is no metabolite; this proved that lindane is completely degraded by this fungus [102]. In a study of atrazine (AT) and alachlor (AL), their degradation by treating them with extracellular enzyme extracted from fungi was determined [103]. FDS-1 strain of Burkholderia sp. can degrade nitrophenyl enzymatically at $30^{\circ} \mathrm{C}$ and $\mathrm{pH}$ of 7.0 taken as optimized conditions [104]. Strains of genetically modified bacteria contain enzymes, which potentially can degrade number of pesticides including OPs, carbamates, and pyrethroids [105].

A study revealed that different enzymes specifically degrade different pesticides (OPs) in wheat kernels [106]. Thirty fungal strains were used to investigate degradation rate of Diuron and pyrithiobac-sodium. Results suggested that the highest degrading rate was by ligninolytic enzymes [107]. Enterobacter enzymatically degrades chlorpyrifos and many other OPs. It degrades them and uses them as carbon and phosphorus source (sole source) [108]. Some Gram negative bacteria have ability to degrade dimethoate. They use it as a sole source of carbon. Bacteria hydrolyze insecticide by using different enzymes, namely, phosphatases and esterases [109]. More than 15 fungal strains were capable of degrading different OPs up to $96 \%$ by enzyme catalyzed pathways [110]. Enzymes for the degradation of organochlorinated pesticide are mainly dehydrochlorination enzymes, hydrolytic enzymes, and dehydrogenases. The genes related are Lin family genes with typical functional codes. Further research could be an effective tool for removal of these pesticides [111]. The amino acid sequence of phosphotriesterase mutant is very effective for the application in organophosphorus pesticide degradation [112].

\section{Conclusion}

Decontamination, caused by pesticides usage, of polluted areas is the need of modern age. The applications of conventional means, that is, physicochemical methods, for the degradation of toxic chemicals are not very efficient. These 
methods are expensive and also not friendly to ecosystem. For the degradation of pesticides and ultimate decontamination of polluted areas, biodegradation is becoming a method of choice. For the removal of hazardous chemicals from environment, the usage of biological agents (bacteria, fungi, and enzymes) is very efficient as they are cost-effective as well as ecofriendly. These biological agents have a potential to decompose pesticides into their less toxic byproducts. There is a need of further study for the investigation of mechanisms of microorganisms and their enzymes during degradation process. The understanding of enzymatic actions, especially concepts related to pesticides mechanism of action, resistance, selectivity, tolerance, and environmental fate, has a vital impact on the knowledge of pesticide science and biological applications.

\section{Competing Interests}

The authors declare that there are no competing interests regarding the publication of this paper.

\section{Authors' Contributions}

Muhammad Kashif Javaid, Mehrban Ashiq, and Muhammad Tahir contributed equally to this publication.

\section{Acknowledgments}

The authors wish to thank Dr. Muhammad Danish and Dr. Muhammad Waseem Mumtaz for their valuable support, University of Gujrat for providing lab facilities, and Higher Education Commission of Pakistan for Scholarship, PIN: 1175254-PS7-150.

\section{References}

[1] EPA, "What is a Pesticide," April 2015, http://www.epa.gov.

[2] EPA, "Pesticides industry, sales and usage," April 2015, http:// www.epa.gov.

[3] Y.-H. Liu, Y.-C. Chung, and Y. Xiong, "Purification and characterization of a dimethoate-degrading enzyme of Aspergillus niger ZHY256, isolated from sewage," Applied and Environmental Microbiology, vol. 67, no. 8, pp. 3746-3749, 2001.

[4] M. Bouziani, "Lusage immodéré des pesticides. De graves conséquences sanitaires," Le Guide de la Médecine et de la Santé, Santémaghreb, 2007.

[5] A. Calderbank, "The occurrence and significance of bound pesticide residues in soil," Reviews of Environmental Contamination and Toxicology, vol. 108, pp. 71-103, 1989.

[6] M. M. Veiga, D. M. Silva, L. B. E. Veiga, and M. V. de Castro Faria, "Pesticide pollution in water systems in a small rural community in Southeast Brazil," Cadernos de Saúde Pública, vol. 22, no. 11, pp. 2391-2399, 2006.

[7] J. Johnson and W. G. Ware, Pesticide Litigation Manual 1992 Edition, Clark Boardman Callaghan Environmental Law Series, New York, NY, USA, 1992.

[8] P. K. Gupta, "Pesticide exposure-Indian scene," Toxicology, vol. 198, no. 1-3, pp. 83-90, 2004.
[9] V. Andreu and Y. Picó, "Determination of pesticides and their degradation products in soil," TrAC-Trends in Analytical Chemistry, vol. 23, no. 10-11, pp. 772-789, 2004.

[10] A. Nawab, A. Aleem, and A. Malik, "Determination of organochlorine pesticides in agricultural soil with special reference to $\gamma-\mathrm{HCH}$ degradation by Pseudomonas strains," Bioresource Technology, vol. 88, no. 1, pp. 41-46, 2003.

[11] M. Ashiq, M. Danish, and M. W. Mumtaz, "Particulate matter as potential outdoor pollutant of ambient environment," Journal of Environmental Monitoring, vol. 12, no. 7-8, pp. 4-9, 2012.

[12] M. W. Bashir, M. Ashiq, M. Y. Saddique, M. F. Mukhtar, A. Hassan, and S. U. Islam, "Indoor particulate matter and its characteristics challenging for environmental remediation," International Journal of Ecological Science and Environmental Engineering, vol. 2, no. 6, pp. 48-51, 2015.

[13] G. Hodaifa, L. M. Nieto, and M. S. Casanova, "Elimination of pesticide residues from virgin olive oil by ultraviolet light: preliminary results," Journal of Hazardous Materials, vol. 168, no. 1, pp. 555-559, 2009.

[14] A. Wyss, J. Boucher, A. Montero, and I. Marison, "Microencapsulated organic phase for enhanced bioremediation of hydrophobic organic pollutants," Enzyme and Microbial Technology, vol. 40, no. 1, pp. 25-31, 2006.

[15] T. S. Bhalerao and P. R. Puranik, "Biodegradation of organochlorine pesticide, endosulfan, by a fungal soil isolate, Aspergillus niger," International Biodeterioration and Biodegradation, vol. 59, no. 4, pp. 315-321, 2007.

[16] E. Hodgson, R. M. Roe, D. K. S. Goh, G. C. Rock, and R. L. Rose, "Insect cytochrome P-450: metabolism and resistance to insecticides," Biochemical Society Transactions, vol. 21, no. 4, pp. 1060-1065, 1993.

[17] R. E. Hinchee, D. B. Anderson, F. B. Metting Jr., and G. D. Sayles, Applied Biotechnology for Site Remediation, Lewis, Chelsea, Mich, USA, 1994.

[18] G. R. Chaudhry, Biological Degradation and Bioremediation of Toxic Chemicals, Dioscorides Press, Warsaw, Poland, 1994.

[19] R. M. Surekha, P. K. L. Lakshmi, and D. Suvarnalatha, "Isolation and characterization of a chlorpyrifos degrading bacterium from agricultural soil and its growth response," African Journal of Microbiology, vol. 2, pp. 26-31, 2008.

[20] G. Enrica, "The role of Microorganisms in environmental decontamination," in Contaminants in the Environment: A Multidisciplinary Assessment of Risks to Man and Other Organisms, A. Renzoni, Ed., vol. 25, pp. 235-246, Lewis Publishers, Boca Raton, Fla, USA, 1994.

[21] B. E. Ritmann, D. E. Jacson, and S. L. Storck, "Potential for treatment of hazardous organic chemicals with biological Process," Biotreatment Systems, vol. 3, pp. 15-64, 1988.

[22] G. S. Sayler, S. W. Hooper, A. C. Layton, and J. M. H. King, "Catabolic plasmids of environmental and ecological significance," Microbial Ecology, vol. 19, no. 1, pp. 1-20, 1990.

[23] Z. Chishti, S. Hussain, K. R. Arshad, A. Khalid, and M. Arshad, "Microbial degradation of chlorpyrifos in liquid media and soil," Journal of Environmental Management, vol. 114, pp. 372-380, 2013.

[24] Z.-1. Cui, L.-x. Cui, Y. Huang, X. Yan, J. He, and S.-p. Li, "Advances and application of microbial degradation in pesticides pollution remediation," Nanjing Nongye Daxue Xuebao, vol. 35, no. 5, pp. 93-102, 2012.

[25] L. S. Tian and F. Chen, "Biological characteristics and degradation performance of a degrading strain," Yangzhou Daxue Xuebao, vol. 33, no. 1, pp. 86-90, 2012. 
[26] J. Jiang, B. Yang, F. Fan et al., "Method for using alfalfaorganophosphorus pesticide degradation bacteria to jointly renovate organophosphorus pesticide contaminated soil," Faming Zhuanli Shenqing, CN 102755991 B, 2012.

[27] P. Zhao, Q. Wen-jing, Y. Wang et al., "Isolation and identification of two strains capable of degrading of organophosphorus pesticides and their biodegradation abilities," Lanzhou LigongDaxue Xuebao, vol. 36, no. 3, pp. 86-90, 2012.

[28] Z. Liu, C. Yang, and Ch.-L. Qiao, "Biodegradation of $p$ nitrophenol and 4-chlorophenol by Stenotrophomonas sp," FEMS Microbiology Letters, vol. 277, no. 2, pp. 150-156, 2007.

[29] G. Madhuban, D. Debashis, and S. K. Das, "Biodegradation of imidacloprid and metribuzin by Burkholderia cepacia strain CH9," Pesticide Research Journal, vol. 23, no. 1, pp. 36-40, 2011.

[30] L. Tingting, D. Kunming, L. Miao et al., "Isolation, identification and biodegradation characteristics of a bacterial strain able to degrade bifenthrin," Nongye Huanjing KexueXuebao, vol. 31, no. 6, pp. 1147-1152, 2012.

[31] G. Briceño, M. S. Fuentes, G. Palma, M. A. Jorquera, M. J. Amoroso, and M. C. Diez, "Chlorpyrifos biodegradation and 3,5,6-trichloro-2-pyridinol production by actinobacteria isolated from soil," International Biodeterioration and Biodegradation, vol. 73, pp. 1-7, 2012.

[32] R. Karthikeyan and S. L. Hutchinson, "Biodegradation of tertiary butyl mercaptan in water," Journal of Bioremediation and Biodegradation, vol. 3, no. 6, p. 156, 2012.

[33] O. K. Mbogo, G. Magoma, K. Ngamau et al., "Characterization of methomyl and carbofuran degrading-bacteria from soils of horticultural farms in Rift Valley and Central Kenya," African Journal of Environmental Science and Technology, vol. 6, no. 2, pp. 104-114, 2012.

[34] S. Kumar, A. Anthonisamy, and S. Arunkumar, "Biodegradation of methyl parathion and endosulfan using: Pseudomonas aeruginosa and Trichodermaviridae," Journal of Environmental Science and Engineering, vol. 53, no. 1, pp. 115-122, 2011.

[35] L. Yin, X. Li, Y. Liu, D. Zhang, S. Zhang, and X. Luo, "Biodegradation of cypermethrin by rhodopseudomonas palustris GJ22 isolated from activated sludge," Fresenius Environmental Bulletin A, vol. 21, no. 2, pp. 397-405, 2012.

[36] A. Soromotin, L. Ogurtsova, T. Morozova, and E. B. Zhdanova, "Method of microbiological degradation of organochlorine pesticides," Russian Patent 2448786, 2012.

[37] J. C. Mendoza, Y. Perea, and J. A. Salvador, "Bacterial biodegradation of permetrina and cipermetrina pesticides in a culture assemblage," Avances en Ciencias e Ingenieria, vol. 2, no. 3, pp. 45-55, 2011.

[38] M. Wang, G. Yang, X. Wang, Y. Yao, H. Min, and Z. Lu, "Nicotine degradation by two novel bacterial isolates of Acinetobacter sp. TW and Sphingomonas sp. TY and their responses in the presence of neonicotinoid insecticides," World Journal of Microbiology and Biotechnology, vol. 27, no. 7, pp. 1633-1640, 2011.

[39] S. Chen, K. Lai, Y. Li, M. Hu, Y. Zhang, and Y. Zeng, "Biodegradation of deltamethrin and its hydrolysis product 3phenoxybenzaldehyde by a newly isolated Streptomyces aureus strain HP-S-01," Applied Microbiology and Biotechnology, vol. 90, no. 4, pp. 1471-1483, 2011.

[40] A. E. Abo-Amer, "Biodegradation of diazinon by Serratia marcescens DI101 and its use in bioremediation of contaminated environment," Journal of Microbiology and Biotechnology, vol. 21, no. 1, pp. 71-80, 2011.
[41] S. Malghani, N. Chatterjee, H. X. Yu, and Z. Luo, "Isolation and identification of profenofos degrading bacteria," Brazilian Journal of Microbiology, vol. 40, no. 4, pp. 893-900, 2009.

[42] L. Qiao and J. Wang, "Biodegradation characterization of a pyridine-degrading strain," Qinghua Daxue Xuebao, vol. 50, no. 6, pp. 869-872, 2010.

[43] M. Ortiz-Hernandez and E. Sanchez-Salinas, "Biodegradation of the organophosphate pesticide tetrachlorvinphos by bacteria isolated from agricultural soil in Mexico," Revista Internacional de Contaminacion Ambiental, vol. 26, no. 1, pp. 27-38, 2010.

[44] C. M. Kye, M. Reukaradhya, K. Islam et al., "Biodegradation of chlorpyrifos by lactic acid bacteria during kimchi fermentation," Journal of Agriculture and Food Chemistry, vol. 57, no. 5, pp. 1882-1889, 2009.

[45] M. Lio and X. Xie, "Application of enterobacteraerogenes in degrading pyrethroid pesticide residue, and preparation with enterobacteraerogenes," Faming Zhuanli Shenqing, CN102021135 A, 2009.

[46] S. Xie, J. Liu, L. Li, and C. Qiao, "Biodegradation of malathion by Acinetobacter johnsonii MA19 and optimization of cometabolism substrates," Journal of Environmental Sciences, vol. 21, no. 1, pp. 76-82, 2009.

[47] J. Zhang, Z. Sun, Y. Li, X. Peng, W. Li, and Y. Yan, "Biodegradation of $p$-nitrophenol by Rhodococcus sp. CN6 with high cell surface hydrophobicity," Journal of Hazardous Materials, vol. 163, no. 2-3, pp. 723-728, 2009.

[48] A. Sabdono and O. K. Radjasa, "Phylogenetic diversity of organophosphorous pesticide-degrading coral bacteria from Mid-West Coast of Indonesia," Biotechnology, vol. 7, no. 4, pp. 694-701, 2008.

[49] K. Zeinat, A. H. Nashwa, and M. Ibrahim, "Biodegradation and detoxification of malathion by of bacillus thuringiensis MOS-5," Australian Journal of Basic and Applied Sciences, vol. 2, no. 3, pp. 724-732, 2008.

[50] J. Ha, C. R. Engler, and J. R. Wild, "Biodegradation of coumaphos, chlorferon, and diethylthiophosphate using bacteria immobilized in Ca-alginate gel beads," Bioresource Technology, vol. 100, no. 3, pp. 1138-1142, 2009.

[51] T. P. Cáceres, M. Megharaj, and R. Naidu, "Biodegradation of the pesticide fenamiphos by ten different species of green algae and cyanobacteria," Current Microbiology, vol. 57, no. 6, pp. 643646, 2008.

[52] P. W. Savadogo, A. Savadogo, A. S. Ouattara, M. P. Sedogo, and A. S. Traoré, "Anaerobic biodegradation of sumithion an organophosphorus insecticide used in Burkina Faso agriculture by acclimatized indigenous bacteria," Pakistan Journal of Biological Sciences, vol. 10, no. 11, pp. 1896-1905, 2007.

[53] B. E. Barragán-Huerta, C. Costa-Pérez, J. Peralta-Cruz, J. Barrera-Cortés, F. Esparza-García, and R. Rodríguez-Vázquez, "Biodegradation of organochlorine pesticides by bacteria grown in microniches of the porous structure of green bean coffee," International Biodeterioration and Biodegradation, vol. 59, no. 3, pp. 239-244, 2007.

[54] V. Prabakaran and A. Peterson, "Effect of Pseudomonas on biodegradation of pesticide in the fish Cyprinus carpio," Journal of Ecotoxicology and Environmental Monitoring, vol. 16, no. 5, pp. 475-479, 2006.

[55] V. Prabakaran and A. Peterson, "Effect of Pseudomonas on biodegradation of pesticide in the fish Cyprinus carpio," Journal of Ecotoxicology and Environmental Monitoring, vol. 16, no. 5, pp. 459-464, 2006. 
[56] H. M. Shivaramaiah and I. R. Kennedy, "Biodegradation of endosulfan by a soil bacterium," Journal of Environmental Science and Health Part B: Pesticides, Food Contaminants, and Agricultural Wastes, vol. 41, no. 6, pp. 895-905, 2006.

[57] L. Shunpeng and Z. Mingxing, "Sphingomonas strain for degrading chlorophenothane pesticide residue and bacteria agent containing this strain," Faming Zhuanli Shenqing Gongkai Shuomingshu, 2006.

[58] N. Harada, K. Takagi, A. Harazono, K. Fujii, and A. Iwasaki, "Isolation and characterization of microorganisms capable of hydrolysing the herbicide mefenacet," Soil Biology and Biochemistry, vol. 38, no. 1, pp. 173-179, 2006.

[59] C. Shengwen, L. Weiping, and Z. Anping, "Enantioselective biodegradation of metalaxyl by sewage sludge and screening bacteria," in Proceedings of the 231st ACS National Meeting, Abstracts of Papers, Atlanta, Ga, USA, March 2006.

[60] J. Liu, L. Wang, L. Zheng, X. Wang, and F. S. C. Lee, "Analysis of bacteria degradation products of methyl parathion by liquid chromatography/electrospray time-of-flight mass spectrometry and gas chromatography/mass spectrometry," Journal of Chromatography A, vol. 1137, no. 2, pp. 180-187, 2006.

[61] D. Zhang, T. Xinqiu, and L. Xiangwen, "Isolation of photosynthetic bacteria HP-1 with degradation of organicphosphorus insecticides and studies on its biodegradation ability and capacity of increasing growth," Shengming Kexue Yanjiu, vol. 9, no. 3, pp. 247-253, 2005.

[62] L. Shunpeng and L. Z. Shen, "Pseudomonas putida and its bacterial products for degrading organophosphorus pesticide residues," Faming Zhuanli Shenqing Gongkai Shuomingshu, 2005.

[63] D. K. Li and K. W. Rutherford, "In situ anaerobic-aerobic process for the biodegradation of chlorinated pesticides in soil: in situ and on-site bioremediation," in Proceedings of the 8th International In Situ and On-Site Bioremediation Symposium, Baltimore, Md, USA, June 2005.

[64] M. Paingankar, M. Jain, and D. Deobagkar, "Biodegradation of allethrin, a pyrethroid insecticide, by an Acidomonas sp.", Biotechnology Letters, vol. 27, no. 23-24, pp. 1909-1913, 2005.

[65] L. Ning, C. Jing-ying, and L. Li, "Isolation and selection of strains used to degrade organic PCNB pesticides and their application effects," Jilin Nongye Daxue Xuebao, vol. 27, no. 2, pp. 205-208, 2005.

[66] D. G. Karpouzas, A. Fotopoulou, U. Menkissoglu-Spiroudi, and B. K. Singh, "Non-specific biodegradation of the organophosphorus pesticides, cadusafos and ethoprophos, by two bacterial isolates," FEMS Microbiology Ecology, vol. 53, no. 3, pp. 369-378, 2005.

[67] A. Pattanasupong, H. Nagase, M. Inoue et al., "Biodegradation of persistent pesticides by immobilized microbial consortia for use in paddy fields," Biotechnology for Sustainable Utilization of Biological Resources in the Tropics, vol. 17, pp. 421-425, 2004.

[68] A. Pattanasupong, H. Nagase, M. Inoue et al., "Ability of a microbial consortium to remove pesticide, carbendazim and 2,4-dichlorophenoxyacetic acid," World Journal of Microbiology and Biotechnology, vol. 20, no. 5, pp. 517-522, 2004.

[69] W. Guohui, Selection of High Efficient Degrading Strains and Study on Its Degrading Capability, vol. 8, Huanjing Baohu, Beijing, China, 2004.

[70] X. Zhang, W. Wu, Y. Zhang et al., "Screening of efficient hydrocarbon-degrading strains and study on influence factors of degradation of refinery oily sludge," Industrial and Engineering Chemistry Research, vol. 46, no. 26, pp. 8910-8917, 2007.
[71] L. J. R. Foster, B. H. Kwan, and T. Vancov, "Microbial degradation of the organophosphate pesticide," FEMS Microbiology Letters, vol. 240, no. 1, pp. 49-53, 2004.

[72] K. R. Krishna and L. Philip, "Biodegradation of mixed pesticides by mixed pesticide enriched cultures," Journal of Environmental Science and Health-Part B: Pesticides, Food Contaminants, and Agricultural Wastes, vol. 44, no. 1, pp. 18-30, 2009.

[73] H. Li, W. Liang, X. Wu, and Y. Liu, "Research on biodegradation of organophosphorus insecticide by a novel psychrotrophic bacterium SA-8," Zhongshan Daxue Xuebao, Ziran Kexueban, vol. 43, no. 3, pp. 131-132, 2004.

[74] A. Singh, J. A. Ranjit, P. Dhasarathan et al., "Isolation and characterization of pesticide metabolizing bacteria from groundnut soil system," Asian Journal of Microbiology, Biotech and Environmental Science, vol. 5, no. 3, pp. 323-332, 2003.

[75] C.-L. Qiao, Y.-C. Yan, H. Y. Shang, X. T. Zhou, and Y. Zhang, "Biodegradation of pesticides by immobilized recombinant Escherichia coli," Bulletin of Environmental Contamination and Toxicology, vol. 71, no. 2, pp. 370-374, 2003.

[76] U. S. Gupta, "Biodegradation of chlorinated hydrocarbon insecticide by Pseudomonas species," Himalayan Journal of Environmental and Zoology, vol. 19, no. 1, pp. 1-10, 2005.

[77] L. Shun-Peng, Z. Ruifu, J. Jian-Dong et al., "Ochrobactrum MP4 and its products for degrading residues of triazophos-based pesticide," in Faming Zhuanli Shenqing Gongkai Shuomingshu, 2005.

[78] P. Chaudhary, M. Kumar, B. S. Khangarot, and A. Kumar, "Degradation and detoxification of hexachlorocyclohexane isomers by Pseudomonas aeruginosa ITRC-5," International Biodeterioration and Biodegradation, vol. 57, no. 2, pp. 107-113, 2006.

[79] G. Santacruz, E. R. Bandala, and L. G. Torres, "Chlorinated pesticides (2,4-D and DDT) biodegradation at high concentrations using immobilized Pseudomonas fluorescens," Journal of Environmental Science and Health - Part B Pesticides, Food Contaminants, and Agricultural Wastes, vol. 40, no. 4, pp. 571583, 2005.

[80] W. Xue-Dong, O. Xiao-Ming, W. Hui-Li et al., "Optimized cultivation of highly-efficient bacterial strains and their biodegradation ability towards imazapyr," Nongye Huanjing Kexue Xuebao, vol. 22, no. 1, pp. 102-105, 2003.

[81] L. Yu-Suo, X. Yi-Gang, S. Li-Li et al., "Study on biodegradation and removal of pesticide residue in soil and plant system," Nongye Huanjing Kexue Xuebao, vol. 22, no. 2, pp. 221-223, 2003.

[82] M. Atia, N. M. Awad, and A. Z. Turky, "Associative action of growth promoting Rhizobacteria and phytoremediationon the biodegradation of certain pesticides in soil," Bulletin of the National Research Centre Egypt, vol. 27, no. 4, pp. 469-480, 2002.

[83] F. D. M. Guillén-Jiménez, E. Cristiani-Urbina, J. C. CancinoDíaz, J. L. Flores-Moreno, and B. E. Barragán-Huerta, "Lindane biodegradation by the Fusarium verticillioides AT-100 strain, isolated from Agave tequilana leaves: kinetic study and identification of metabolites," International Biodeterioration and Biodegradation, vol. 74, pp. 36-47, 2012.

[84] A. P. Pinto, C. Serrano, T. Pires et al., "Degradation of terbuthylazine, difenoconazole and pendimethalin pesticides by selected fungi cultures," Science of the Total Environment, vol. 435-436, pp. 402-410, 2012.

[85] F. I. Hai, O. Modin, K. Yamamoto, K. Fukushi, F. Nakajima, and L. D. Nghiem, "Pesticide removal by a mixed culture of bacteria 
and white-rot fungi," Journal of the Taiwan Institute of Chemical Engineers, vol. 43, no. 3, pp. 459-462, 2012.

[86] W. O. Nyakundi, G. Magoma, J. Ochora, and A. B. Nyende, "Biodegradation of diazinon and methomyl pesticides by white rot fungi from selected horticultural farms in rift valley," Journal of Applied Technology in Environmental Sanitation, vol. 1, no. 2, pp. 107-124, 2011.

[87] V. Sagar and D. P. Singh, "Biodegradation of lindane pesticide by non white- rots soil fungus Fusarium sp," World Journal of Microbiology and Biotechnology, vol. 27, no. 8, pp. 1747-1754, 2011.

[88] S. N. Ortega, M. Nitschke, A. M. Mouad et al., "Isolation of Brazilian marine fungi capable of growing on DDD pesticide," Biodegradation, vol. 22, no. 1, pp. 43-50, 2011.

[89] R. Kataoka, K. Takagi, and F. Sakakibara, "A new endosulfandegrading fungus, Mortierella species, isolated from a soil contaminated with organochlorine pesticides," Journal of Pesticide Science, vol. 35, no. 3, pp. 326-332, 2010.

[90] G. Kulshrestha and A. Kumari, "Simultaneous degradation of mixed insecticides by mixed fungal culture isolated from sewage sludge," Journal of Agricultural and Food Chemistry, vol. 58, no. 22, pp. 11852-11856, 2010.

[91] Z. C. Ouyang, Y. H. Wang, X. N. Li et al., "Test of pesticide degradability by Sphingomonas yanoikuyae XJ strain," Huanan Nongye Daxue Xuebao, vol. 29, no. 2, pp. 47-49, 2008.

[92] V. V. Chougale and A. M. Deshmukh, "Biodegradation of carbofuran pesticide by saline soil actinomycetes," Asian Journal of Microbiology, Biotechnology and Environmental Sciences, vol. 9, no. 4, pp. 1057-1061, 2007.

[93] M. Slaoui, M. Ouhssine, E. Berny, and M. Elyachioui, "Biodegradation of the carbofuran by a fungus isolated from treated soil," African Journal of Biotechnology, vol. 6, no. 4, pp. 419-423, 2007.

[94] Y. L. Yu, H. Fang, X. Wang, X. M. Wu, M. Shan, and J. Q. $\mathrm{Yu}$, "Characterization of a fungal strain capable of degrading chlorpyrifos and its use in detoxification of the insecticide on vegetables," Biodegradation, vol. 17, no. 5, pp. 487-494, 2006.

[95] J. Seo, Y.-G. Lee, S.-D. Kim, C.-J. Cha, J.-H. Ahn, and H.-G. Hur, "Biodegradation of the insecticide N,N-diethyl-m-toluamide by fungi: identification and toxicity of metabolites," Archives of Environmental Contamination and Toxicology, vol. 48, no. 3, pp. 323-328, 2005.

[96] J. Lipok, I. Dombrovska, P. Wieczorek et al., "The ability of fungi isolated from stored carrot seeds to degrade organophosphonate herbicides," in Pesticide in Air, Plant, Soil and Water System, Proceedings of the 12th Symposium Pesticide Chemistry, Piacenza, Italy, June 4-6, 2003, pp. 575-580, La Goliardica Pavese, 2003.

[97] A. A. A. Romeh, "Biodegradation of carbosulfan, pirimicarb and diniconazole pesticides by Trichoderma spp," Journal of Environmental Research, vol. 3, pp. 162-172, 2001.

[98] B. Z. Li-Qing, J. Hong-Xia, Y. Yan-Chun et al., "Degradation of organophosphorus pesticide by engineered bacteria and immobilized cell," Huanjing Kexue Yu Jishu, vol. 31, no. 5, pp. 45-48, 2008.

[99] X. Peng, J. S. Zhang, Y. Y. Li, W. Li, G. M. Xu, and Y. C. Yan, "Biodegradation of insecticide carbofuran by Paracoccus sp. YM3," Journal of Environmental Science and Health B, vol. 43, no. 7, pp. 588-594, 2008.

[100] H. Zhang, C. Yang, C. Li, L. Li, Q. Zhao, and C. Qiao, "Functional assembly of a microbial consortium with autofluorescent and mineralizing activity for the biodegradation of organophosphates," Journal of Agricultural and Food Chemistry, vol. 56, no. 17, pp. 7897-7902, 2008.

[101] P. N. Tallur, V. B. Megadi, and H. Z. Ninnekar, "Biodegradation of Cypermethrin by Micrococcus sp. strain CPN 1," Biodegradation, vol. 19, no. 1, pp. 77-82, 2008.

[102] V. Nagpal, M. C. Srinivasan, and K. M. Paknikar, "Biodegradation of $\gamma$-hexachlorocyclohexane (Lindane) by a non-white rot fungus conidiobolus 03-1-56 isolated from litter," Indian Journal of Microbiology, vol. 48, no. 1, pp. 134-141, 2008.

[103] A. E. M. Chirnside, W. F. Ritter, and M. Radosevich, "Bioremediation strategies for pesticide-contaminated Soil: IV. Biodegradation using a selected microbial consortium following pretreatment with fungal Enzymes," in Proceedings of the 9th International In Situ and On-Site Bioremediation Symposium, pp. 1233-1240, Baltimore, Md, USA, May 2007.

[104] W. S. Lan, J. D. Gu, J. L. Zhang et al., "Coexpression of two detoxifying pesticide-degrading enzymes in a genetically engineered bacterium," International Biodeterioration and Biodegradation, vol. 58, no. 2, pp. 70-76, 2006.

[105] Z. Liu, Q. Hong, J.-H. Xu, W. Jun, and S.-P. Li, “Construction of a genetically engineered microorganism for degrading organophosphate and carbamate pesticides," International Biodeterioration and Biodegradation, vol. 58, no. 2, pp. 65-69, 2006.

[106] K. Yoshii, Y. Tonogai, H. Ueno, and K. Nakamuro, "Malathion residue in wheat kernels is degraded by thion organophosphorus pesticide-specific carboxylesterase," Journal of Health Science, vol. 52, no. 3, pp. 221-227, 2006.

[107] M. A. Gondim-Tomaz, T. T. Franco, and L. R. Durrant, "Biodegradation of diuron and pyruthiobac-sodium by whiterot and soil fungi," Contaminated Soils, Sediments and Water, vol. 9, pp. 21-32, 2005.

[108] B. K. Singh, A. Walker, J. A. W. Morgan, and D. J. Wright, "Biodegradation of chlorpyrifos by Enterobacter strain B-14 and its use in bioremediation of contaminated soils," Applied and Environmental Microbiology, vol. 70, no. 8, pp. 4855-4863, 2004.

[109] T. A. Kadam, V. D. Jadhav, and G. Gyananath, "Microbial degradation of dimethoate by gram negative soil isolates from cotton field," Pollution Research, vol. 22, no. 3, pp. 443-445, 2003.

[110] J. Jauregui, B. Valderrama, A. Albores, and R. Vazquez-Duhalt, "Microsomal transformation of organophosphorus pesticides by white rot fungi," Biodegradation, vol. 14, no. 6, pp. 397-406, 2003.

[111] F. Y. Zhang, Y. A. Jiao, and Y. Guangyu, "Sequence of Geobacillus phosphotriesterase mutant and its uses in decomposing organophosphorus pesticide," Faming Zhuanli Shenqing, 2012.

[112] L. Xiang-Ming and C. Ping-Ping, "Progress in degradation of organo-chlorinated pesticides by microorganism," Huanjing Kexue Yu Jishu, vol. 35, no. 6, pp. 89-93, 2012. 


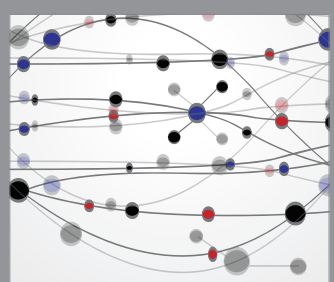

The Scientific World Journal
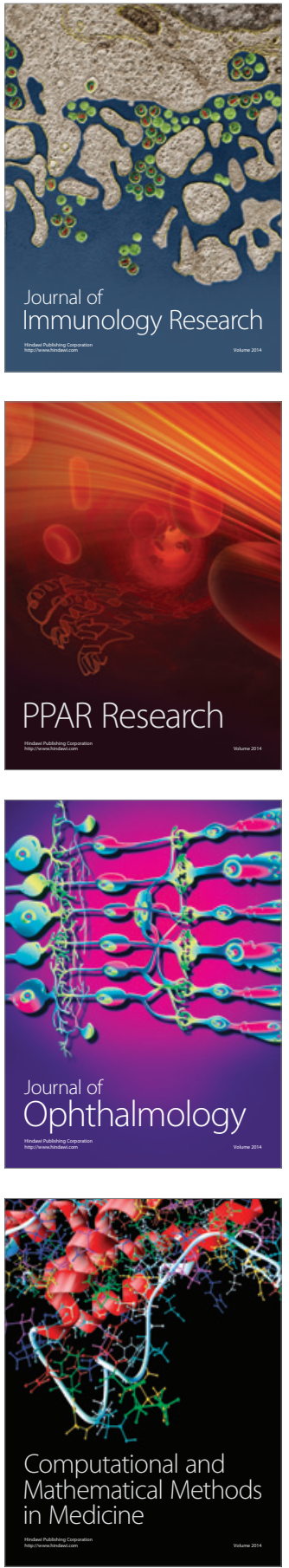

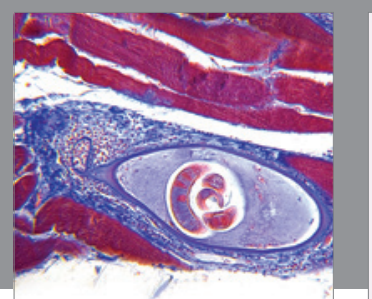

Gastroenterology Research and Practice

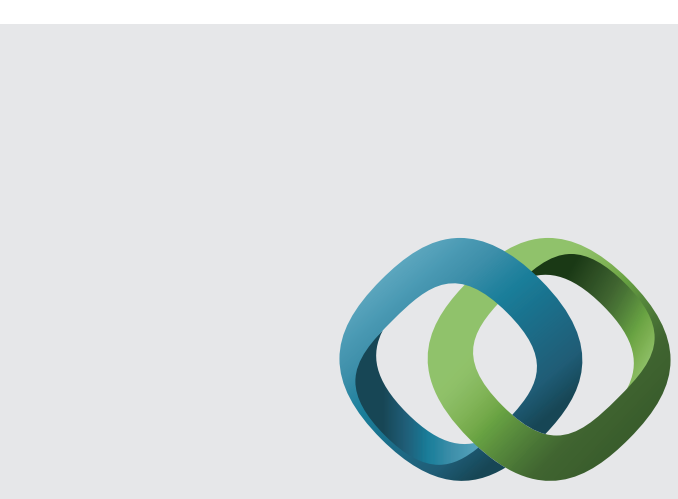

\section{Hindawi}

Submit your manuscripts at

http://www.hindawi.com
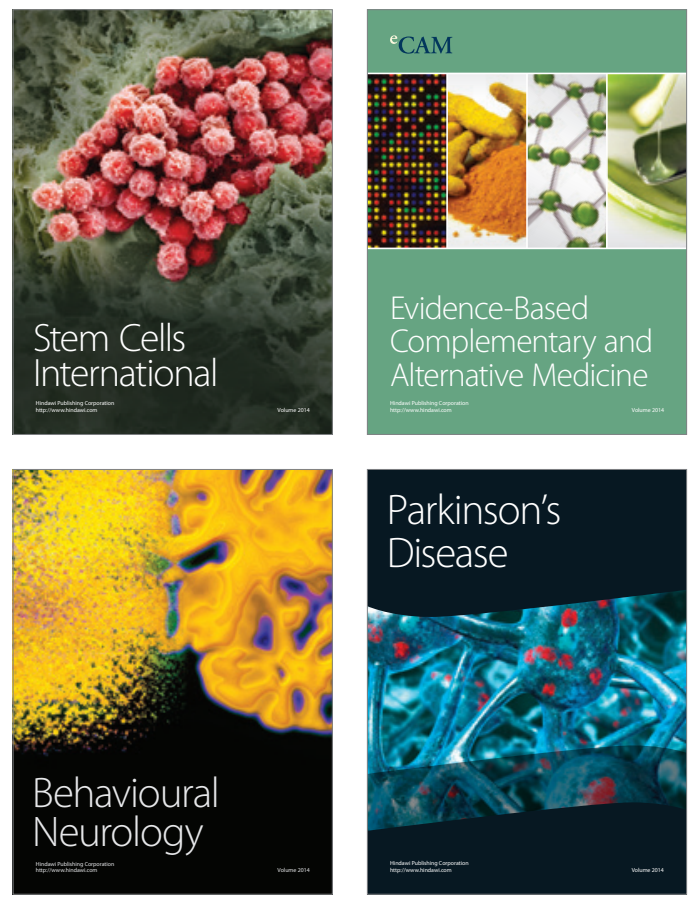
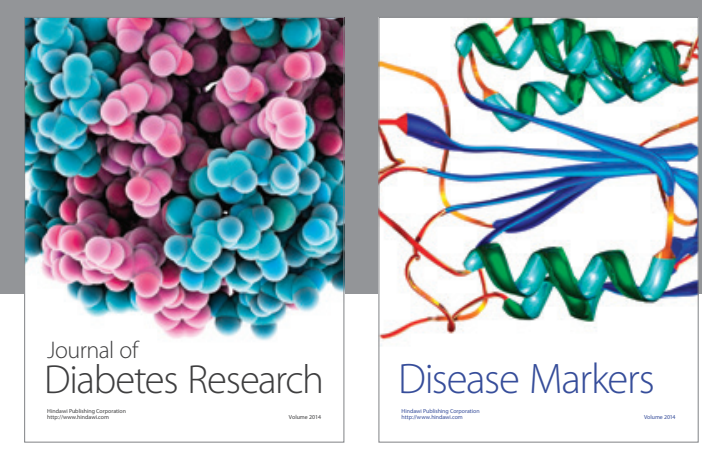

Disease Markers
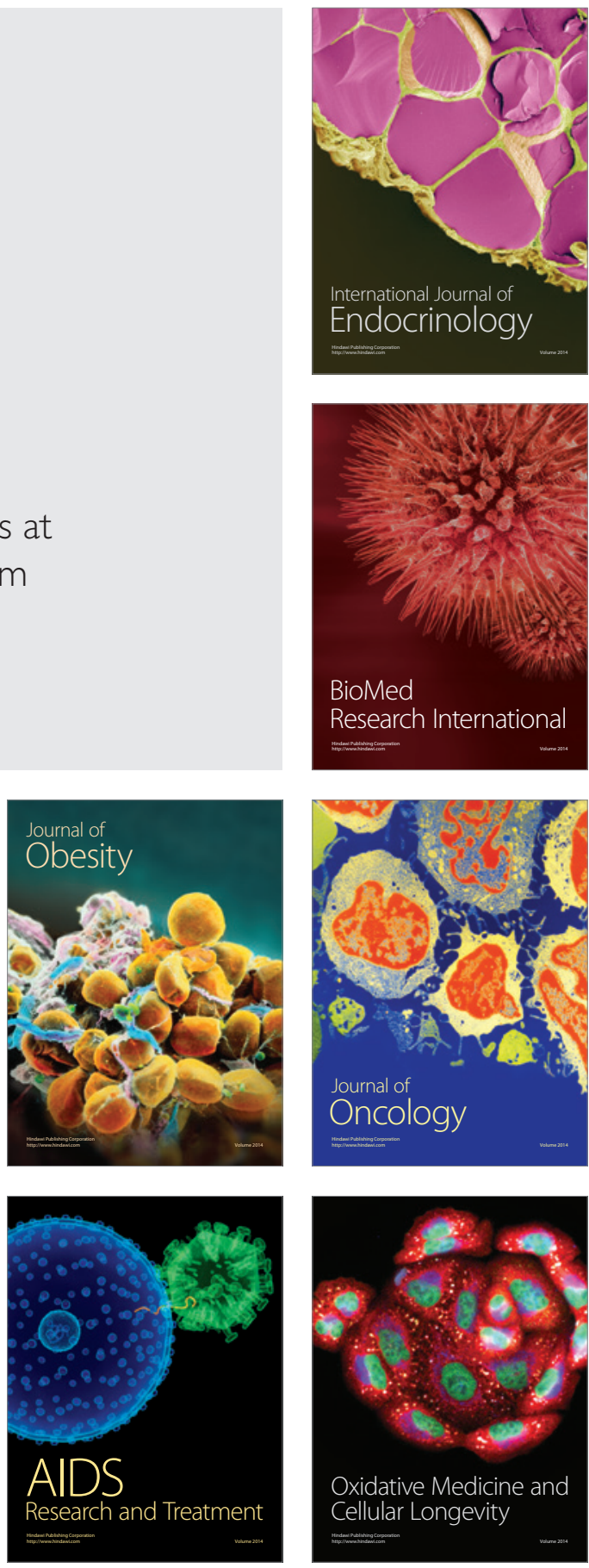